\title{
Systematic comparison of hydrogen production from fossil fuels and biomass resources
}

\author{
Kang Peng ${ }^{1}$, Gary Morrow ${ }^{2}$, Zhang Xiaolei ${ }^{2 *}$, Wang Tipeng ${ }^{3}$, \\ Tan Zhongfu ${ }^{1}$, Jayant Agarwal ${ }^{4}$
}

\begin{abstract}
(1. Institute of Energy Economics and Environment, School of Economics and Management, North China Electric Power University, Beijing 102206, China; 2. School of Mechanical and Aerospace Engineering, Queen's University Belfast, Belfast BT9 5AH, United Kingdom; 3. National Engineering Laboratory for Biomass Power Generation Equipment, School of Renewable Energy Engineering, North China Electric Power University, Beijing 102206, China;

4. Department of Mechanical Engineering, College of Engineering Roorkee, Uttarakhand 247667, India)
\end{abstract}

\begin{abstract}
Fossil fuels are the main energy source to satisfy the worldwide energy demands. However, the energy demands are increasing and the supply of fossil fuels is decreasing, thus many countries are looking for other fuel sources. Differing from the traditional fuels, hydrogen is considered as one of the most promising energy sources due to its intrinsic features such as clean, efficient, safe and sustainable. Developing novel technologies for hydrogen production from renewable sources (such as biomass) becomes a core area for the investigation of hydrogen industry. Within this work, different pathways for hydrogen production including steam reforming, electrolysis, and biomass gasification have been systematically compared in terms of yield and cost. This comparison is unique since the systematic evaluation was conducted from many aspects for all the hydrogen production pathways, especially those by involving the biomass gasification that still lack of available literatures. The assessment methods involved energy analysis, exergy analysis and economic analysis. It was concluded that steam reforming remains the cheapest method of hydrogen production at $1.748 \$ / \mathrm{kg}$, however, steam reforming is not an ideal process currently or for the future, gasification and electrolysis remains competitive with high yield but requires relatively high initial and annual expenditure. For biomass gasification, though its energy efficiency is lower than steam reforming, it has relatively higher mass yield, demonstrating the feasibility of this process for hydrogen production. Further for biomass gasification, the selection of correct feedstock is a key to maximize its yield, i.e. a yield of $82.47 \%$ is possible with corn stover fed gasification.
\end{abstract} Keywords: hydrogen production, biomass feedstock, gasification, pyrolysis, fossil fuel, techno-economic assessment, exergy DOI: $10.25165 /$ j.jjabe. 20171006.2990

Citation: Kang P, Morrow G, Zhang X L, Wang T P, Tan Z F, Agarwal J. Systematic comparison of hydrogen production from fossil fuels and biomass resources. Int J Agric \& Biol Eng, 2017; 10(6): 192-200.

\section{Introduction}

The worldwide energy demand has risen dramatically due to an increasing industrialisation of more and more countries. Most of the world energy demand is currently

\section{Received date: 2016-11-11 Accepted date: 2017-06-14}

Biographies: Kang Peng, PhD, research interests: lignocellulose mechanism and economics research, Email: kangpeng19821125@ 163.com; Gary Morrow, Master, research interests: hydrogen production from renewable materials, Email: gary.morrow@ qub.ac.uk; Wang Tipeng, Associate Professor, research interests: lignocellulose utilization, Email: wtp_771210@163.com; Tan Zhongfu, Professor, research interests: energy economics, Email: met by the utilization of fossil fuel, which leads to deteriorating environmental problems such as excessive $\mathrm{CO}_{2}$ levels and other noxious gases. Therefore, global effort is being made to find a sustainable replacement for fossil fuels which is less polluting and cost effective.

tanzhongfubeijing@126.com; Jayant Agarwal, Master, research interests: biomass conversion, Email: jayantpkagarwal@gmail.com. *Corresponding author: Zhang Xiaolei, Lecturer, research interests: clean energies, School of Mechanical and Aerospace Engineering, Queen's University Belfast, Ashby Building 06.020, BT9 5AH, Belfast, Northern Ireland. Tel/Fax: +44(0)28 9097 4490, Email: xiaolei.zhang@qub.ac.uk. 
Hydrogen is seen as one of the leading energy alternatives since its combustion only produces water which is much cleaner than carbon dioxide that being produced from fossil fuel. However, many technologies of hydrogen production encounter problems due to not being economically viable or the complexity of the technology involved. Currently, hydrogen is being produced in industry, for example, hydrogen production is firmly established in the $\mathrm{USA}^{[1]}$, however, the production is primarily from fossil fuels, specifically coal $^{[2,3]}$, via a traditional technology called steam reforming. For this technology, the environmental benefits of the downstream hydrogen utilization are diminished. Therefore, to be commercially viable, hydrogen needs to be produced in large quantities at a relatively low cost and environmental-friendly way, one possible solution to this is to use a renewable fuel source $^{[4]}$, such as biomass as a feedstock, instead of fossil fuels.

Currently hydrogen demand is met by the steam reforming of coal or natural gas/methane. Steam reforming process has been favoured for large scale production $^{[5]}$, particularly in petroleum refineries. The methane is fed into the steam reformer, where it reacts with high temperature steam $\left(700^{\circ} \mathrm{C}-1100^{\circ} \mathrm{C}\right)$ in an endothermic reaction to produce synthetic gas (syngas). Syngas is a mixture of carbon monoxide and hydrogen. To increase hydrogen production, after steam reforming, water gas shift reaction is performed at $360^{\circ} \mathrm{C}^{[6]}$. During the process different catalysts are used to maximize hydrogen yield and limit other products being formed $^{[7]}$. Whilst steam reforming is an industrial proven process, the associated $\mathrm{CO}_{2}$ production is high due to the utilization of fossil fuels. It is possible to reduce the carbon released into the atmosphere by retrofitting/implementing carbon capture and storage equipment.

There are some potential ways to produce hydrogen from biomass, and pyrolysis is one of them. Pyrolysis involves the heating of biomass feedstock, at temperature of $377^{\circ} \mathrm{C}-527^{\circ} \mathrm{C}$ and pressure of $0.1-0.5 \mathrm{MPa}$ in the absence of air. For hydrogen production, high temperature, relatively higher heating rate and longer volatile phase residence time are required ${ }^{[8]}$. To maximise hydrogen yield a water-gas shift reaction can also be performed ${ }^{[9]}$. As the pyrolysis pathway has not been fully developed for hydrogen production in industry, however, numerous experiments have been conducted allowing estimates and projections to be established. Padró ${ }^{[10]}$ estimated hydrogen production cost of biomass pyrolysis to be in range of $7.26 \$ / G J$ to $12.68 \$ / G J$ depending on facility size and biomass type. The findings state that the use of biomass should be feasible when compared to existing methods on cost grounds.

Gasification is another potential technology for production of hydrogen from biomass. Gasification takes place above $850^{\circ} \mathrm{C}$ in low oxygen conditions. Similar to pyrolysis, the gaseous mixture produced from gasification can also be steam reformed to increase hydrogen yield ${ }^{[11,12]}$. The yield can be further improved by conducting a water-gas shift reaction. The gasification process is applicable to biomass having moisture content less than $35 \%^{[13]}$. This could make gasification less attractive to companies who do not have facilities to remove moisture of feedstock onsite ${ }^{[14]}$. Estimated cost of hydrogen production from biomass ${ }^{[15]}$ gasification are seen to be similar to natural gas reforming, this means that there is likely to be no negative profit detriment for companies to switch from traditional methods of production during normal machine replacement/ modernisation.

Another technology for hydrogen production is electrolysis. It involves the use of electricity, to split $\mathrm{H}_{2} \mathrm{O}$ into hydrogen and oxygen, using an electrolyser. Due to broader operating conditions, peak efficiency is slightly reduced and the equipment cost is high ${ }^{[16]}$. By considering the environmental benefits for electrolysis, it is possible to use biomass as the source for electricity production. In this case, without considering the energy used to produce the equipment, electrolysis is a zero emission process ${ }^{[17]}$ when the electricity is supplied by a renewable biomass source.

As a summary, there is a potential to produce hydrogen from renewable source at an industrial level via the aforementioned pathways. However, few studies have systematically evaluated those pathways from both 
technical and economic aspects. This research focuses on hydrogen production from lignocellulosic biomass feedstock, especially on those pathways which are emerging as viable ways of mass production in terms of cost and yield. Through analysis, a comparison will be made on pathways fuelled by biomass and those currently fuelled by fossil fuels. The comparison of biomass feedstock is also carried to assess pathways of hydrogen production. Exergy analysis will be conducted, producing a techno-economic assessment for industrial sized applications compared with current methods and determining the suitability of each pathway for hydrogen production.

\section{Materials and methods}

\subsection{Biomass feedstock}

Biomass feedstocks involve energy crops, agricultural residues, forestry waste and residues, industrial and municipal waste. Within this research, three typical biomass feedstocks are selected: poplar, sugar cane and corn stover. Their compositions ${ }^{[18]}$ including the moisture content and the $\mathrm{C}, \mathrm{H}, \mathrm{O}$ content are listed in Table 1.

Table 1 Biomass feedstock compositions ${ }^{[18]}$

\begin{tabular}{cccc}
\hline $\begin{array}{c}\text { Components type in feedstock } \\
\text { (as received basis) }\end{array}$ & Poplar & Sugar cane & Corn stover \\
\hline Moisture/\% & $8-58$ & $16-50$ & $11-33$ \\
Carbon/\% & $47-52$ & $38-55$ & $40-51$ \\
Hydrogen/\% & $5.6-7.3$ & $5.3-6.7$ & $4.7-6.3$ \\
Oxygen/\% & $40-46$ & $33-50$ & $34-50$ \\
\hline
\end{tabular}

\subsection{Methodology}

The aforementioned pathways for hydrogen production need to be systematically assessed to finalize the sustainable industrial scale hydrogen production pathway. As shown in Figure 1, this assessment will be carried out from three aspects: energy analysis, exergy analysis and economic analysis.

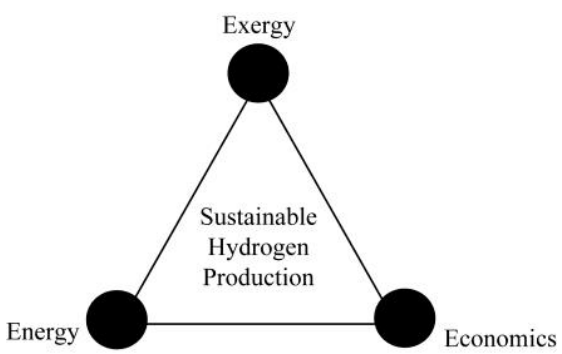

Figure 1 Key elements determining suitable hydrogen pathways

\subsubsection{Energy analysis}

The energy available for extraction in biomass will determine the reaction yield and ultimate hydrogen production. The energy analysis model developed in this research is versatile to allow different biomass types to be input. The energy contained in biomass will be calculated using ultimate analysis, as previously mentioned. As energy will inevitably be lost through the entire process, for example, large energy losses can occur when reactions are uncontrolled and also result in undesirable by-products being produced, measures were put in place to minimize the lost to increase the efficiency. For various biomass feedstocks, there will be variation in energy loss depending on the source of supply due to the change in moisture content of the feedstock.

For the heating value of biomass feedstock, two type of value are normally considered: higher heating value (HHV) and lower heating value (LHV). HHV is equal to LHV multiplies by the vaporization of the water content in the feedstock, as shown in Equation (1) ${ }^{[19]}$.

$$
\begin{gathered}
L H V=H H V-0.212 H-0.0245 M-0.008 Y \\
\eta_{\text {energy }}=\frac{\dot{m}_{H_{2}} \cdot L H V_{H_{2}}}{\dot{m}_{\text {bio }} \cdot L H V_{\text {bio }}+H_{\text {agent }}}
\end{gathered}
$$

where, $L H V$ and $H H V$ are in the unit of $\mathrm{MJ} / \mathrm{kg} ; H$ represents the percentage of hydrogen; $M$ represents the percentage of moisture; and $Y$ represents the percentage of oxygen, all in a received basis.

As for the energy efficiency can be calculated using Equation $(2)^{[20]}$. Where $\dot{m}_{\text {bio }}$ and $\dot{m}_{H_{2}}($ in $\mathrm{kg} / \mathrm{s}$ ) are the mass flow rates of biomass and produced syngas. $L H V_{\text {bio }}\left(17.76 \mathrm{MJ} / \mathrm{kg}\right.$ ) and $L H V_{\mathrm{H} 2}$ (in $\mathrm{MJ} / \mathrm{kg}$ ) are the lower heating values of biomass and produced syngas, respectively; and $H_{\text {agent }}$ (in $\mathrm{MJ} / \mathrm{s}$ ) is the energy flow supplied by the high temperature gasifying agent.

\subsubsection{Exergy analysis}

The exergy of the biomass must be considered to determine the potential hydrogen yield from any proposed industrial site. Exergy is defined as the maximum usable work gained by bringing a system into equilibrium with its environment, the energy that can be used. Exergy analysis brings elements of conservation of mass, conservation of energy and the second law of 
thermodynamics together to form a complete analysis.

From the definition, it can be seen that exergy must be measured in relation to its immediate environment. Therefore it is necessary for a specified temperature, pressure and chemical composition of this reference environment to be obtained. The exergy values of chemicals will be obtained, for biomass, average values will be taken.

Similar to energy efficiency, the total exergy efficiency of the process ${ }^{[20]}$ can be defined as:

$$
\eta_{\text {exergy }}=\frac{E x_{\mathrm{H}_{2}}{ }^{c h}}{E x_{\text {bio }}{ }^{c h}+E x_{\text {bio }}{ }^{p h}+E x_{\text {agent }}}
$$

where, $E x_{\text {bio }}, E x_{\text {agent }}, E x_{H 2}$ indicate the exergy of the biomass, gasifying agent, produced hydrogen, respectively. The exergy in a material stream can be calculated as the sum of its chemical exergy $E x^{c h}$ and physical exergy $E x^{p h}$.

$$
E x_{b i o}^{p h}=\int_{T_{0}}^{T} C p_{b i o} d T+T_{0} \int_{T_{0}}^{T} \frac{C p_{b i o}}{T} d T
$$

Within this equation, specified states are characterized by temperature $T$, and the environmental condition with temperature $T_{0}$ is $298 \mathrm{~K}$. and $C_{p}$ is the constant pressure specific heat capacity, $\mathrm{kJ} / \mathrm{kmol} \cdot \mathrm{K}$.

$$
\begin{aligned}
& E x_{b i o}{ }^{c h}=\dot{m}_{b i o} \cdot \beta \cdot L H V_{b i o} \\
& \beta=\frac{1.0414+0.0177\left(\frac{H}{C}\right)-0.3328\left(\frac{O}{C}\right)\left[1+0.0537\left(\frac{H}{C}\right)\right]}{1-0.4021\left(\frac{O}{C}\right)}
\end{aligned}
$$

The formula of correlation factor $\beta$ for biomass is given below, where $\mathrm{C}, \mathrm{H}$ and $\mathrm{O}$ are the molar fractions of $\mathrm{C}, \mathrm{H}$ and $\mathrm{O}$ in biomass, respectively.

\subsubsection{Techno-economic analysis}

The high cost for hydrogen production is currently the biggest barrier for its industrialization, especially when biomass is considered as a feedstock. The production cost varies by site and location due to different infrastructure requirements. For this reason, a comparison must be made to determine the most costly effective method. It may be the case that using cheap feedstock that produces more hydrogen per dollar, or the case of using expensive feedstock with a high hydrogen total yield. This will have to be considered based on availability of feedstock and desired pathway at any given location. The associated production cost would be an indicator in determining the most economical feedstock after the process inefficiencies have been subtracted.

\section{Results and discussion}

The four pathways being considered in this research are: steam reforming without carbon capture and storage (CCS), steam reforming with CCS, biomass gasification and electrolysis. It should be noted that biomass pyrolysis for hydrogen production has not been presented in the results. The reason is that the process is currently only being trialled in small scale test plant ${ }^{[21]}$. There is limited data available of expected yields, set chemical processes and infrastructure required for a general pyrolysis process for hydrogen production at a large scale $^{[22]}$. It has been excluded as a comprehensive model that could not be produced to the same degree as the other processes.

The results within this section are presented based on the analysis methods. First part explains for energy and exergy analysis of all the four selected pathways, second part focuses on the economic analysis of the pathways, the analysis on different feedstock is presented in third part, and the last part provides the suggestions on the opportunity for hydrogen production in the future.

\subsection{Energy and exergy analysis of different pathways}

By quoting data in Table 2 and calculating using forementioned formulas, results of the energy efficiency,

\begin{tabular}{|c|c|c|}
\hline Hydrogen production & Item & Value \\
\hline \multirow{3}{*}{$\begin{array}{l}\text { Inputs of the hydrogen } \\
\text { production from Steam } \\
\text { reforming }\end{array}$} & Fossil fuel consumed/kW'h $\left(\mathrm{t} \mathrm{H}_{2}\right)^{-1}$ & 51207.800 \\
\hline & Fossil fuel input/GW $\cdot h \cdot a^{-1}$ & 1.707 \\
\hline & Steam consumed $/ \mathrm{t} \cdot \mathrm{a}^{-1}$ & 346.993 \\
\hline \multirow{3}{*}{$\begin{array}{l}\text { Inputs of the hydrogen } \\
\text { production from } \\
\text { Electrolysis }\end{array}$} & Water consumed $/ \mathrm{kg} \cdot \mathrm{a}^{-1}$ & 328947.370 \\
\hline & $\mathrm{H}_{2}$ produced $/ \mathrm{kg} \cdot \mathrm{h}^{-1}$ & 4539.525 \\
\hline & Biomass consumed $/ \mathrm{t} \cdot \mathrm{a}^{-1}$ & 47647.060 \\
\hline \multirow{2}{*}{$\begin{array}{l}\text { Inputs of the hydrogen } \\
\text { production from } \\
\text { Biomass gasification }\end{array}$} & Steam consumed $/ \mathrm{t} \cdot \mathrm{a}^{-1}$ & 32.531 \\
\hline & $\begin{array}{l}\mathrm{H}_{2} \text { produced from the water-gas-shift } \\
\text { reaction/t } \cdot \mathrm{a}^{-1}\end{array}$ & 3125.001 \\
\hline
\end{tabular}
exergy efficiency and the mass yield concerning relevant pathways are illustrated in Figure 2.

Table 2 Input parameters of the analysis for three hydrogen 


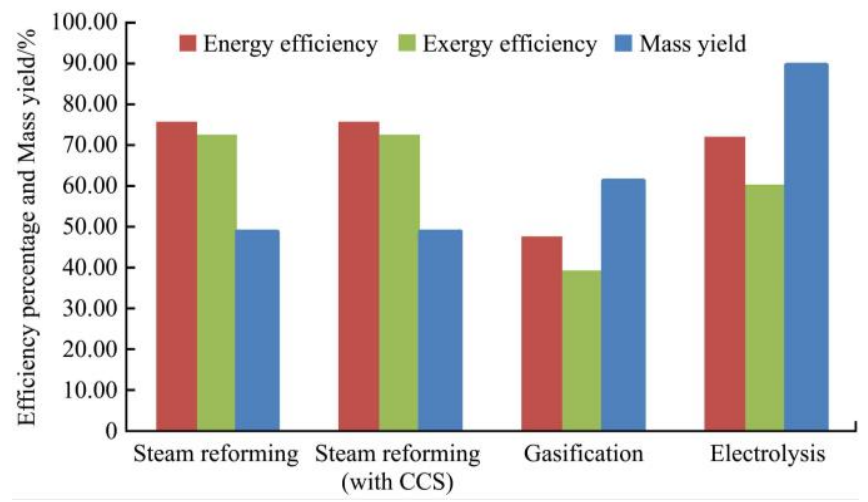

Figure 2 Key efficiencies and mass yields of hydrogen production processes

For the mass yield, it can be seen that electrolysis has a mass yield of $89.7 \%$, which is significant higher than the other processes. This is mainly due to the simpler conversion process of extracting the hydrogen from the water, unlike biomass and natural gas, where the hydrogen is contained within complex chemical structures. Due to this high mass yield, it would be possible to make electrolysis more cost effective if it reached same level of development as steam reforming. The mass yield for the steam reforming processes, either with or without CCS, is generally low, at $49 \%$ in comparison to other pathways.

The exergy value of electrolysis $(60.5 \%)$ is relatively low when compared with other pathways. This is due to the exergy value of water is low, $0.0076 \mathrm{MJ} / \mathrm{kg}$, when compared with the exergy value for biomass ranges at 10-20 MJ/kg. As exergy values for electrolysis are static, to improve this efficiency further, a reduction in electricity used for the conversion would be required. This would be achieved with advancements in electrolyser technology. This would allow maximum hydrogen yield and in parallel, bring down the production cost as more hydrogen would be produced for less electricity.

The energy and exergy efficiencies of gasification are low because of the difficulty in extracting hydrogen from the complex compounds of biomass. A lot of potential energy is lost in the process to extract hydrogen. Selecting high efficient catalyst could improve the gasification conversion process and minimise the char and tar by-products ${ }^{[24]}$. An increased yield and suitable feedstock supply combined with the minimal operating costs would certainly make the gasification process more attractive.

\subsection{Economic analysis of different pathways}

Calculating based on the data in Table 2, results of the cost data concerning four pathways and three biomass feedstocks are illustrated in subsequent. Figures 3 represents the breakdown of expenditure for the initial year of production and the subsequent annual operating costs of the proposed plants. It can be seen that electrolysis has the greatest overall expenditure value both in setup and annual operation. For gasification, the operating cost is very low in comparison to the capital cost. To improve the production cost, gasification would benefit from reduced equipment cost, and so bring it closer to the other pathways. The operating cost of steam reforming with CCS is evident, with an operating cost 20.53 million dollars above conventional reforming to pay for storage and monitoring.

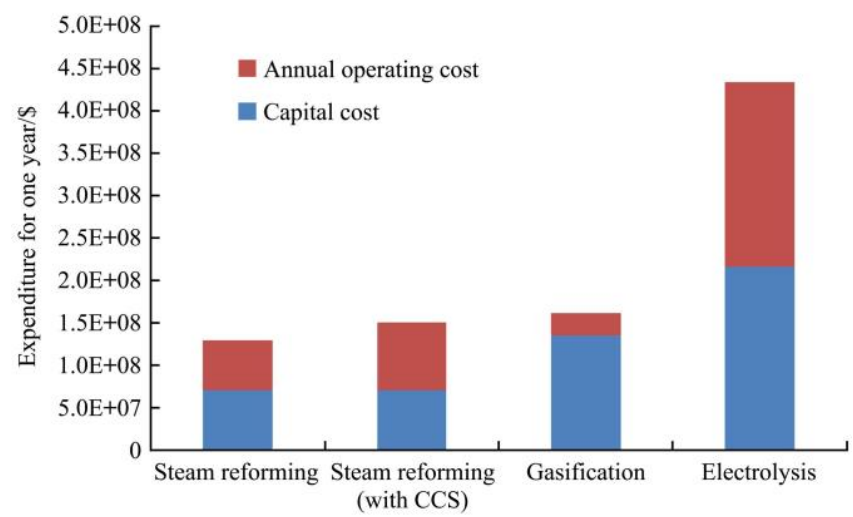

Figure 3 Combined capital and operating costs for one year ${ }^{[23]}$

For a pathway to be attractive for a company to invest and build a plant, it must have a good return. This means that the production cost must be lower than the market value. As the market value varies with demand, it is imperative the production cost be as minimal as possible. Figure 4 shows the estimated production cost of each process. The production cost is presented as the cost to produce a quantity of hydrogen per unit mass, $\$ / \mathrm{kg}$.

Steam reforming can be seen to be the most cost effective per $\mathrm{kg}$ of hydrogen produced at $1.748 \$ / \mathrm{kg}$, this was expected due to it being the current industrial process. It has had both time and money spent to develop the process, techniques and equipment to extract hydrogen as efficiently as possible. However, steam reforming is not 
an ideal process currently or for the future, due to the large quantities of $\mathrm{CO}_{2}$ that are produced as a by-product.

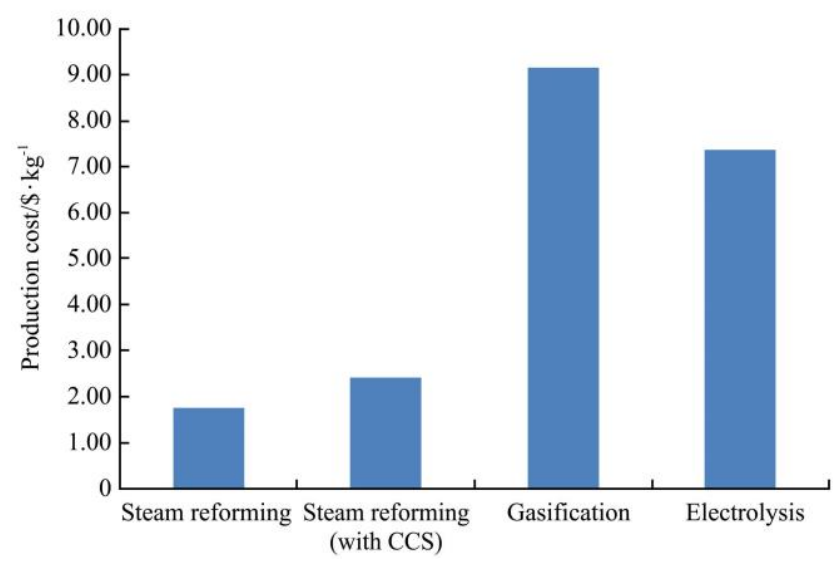

Figure 4 Production costs of four hydrogen production pathways

The production cost of steam reforming with CCS in Figure 4 is higher than conventional steam reforming at $2.41 \$ / \mathrm{kg}$, due to the cost of the compression and storage of the carbon. An advantage of CCS is that the equipment can be retro fitted to an existing reformer plant, allowing companies to maximise return on their current site. Once operational, this would cause an immediate reduction in the amount of carbon released into the atmosphere from a reformer site. Utilising this equipment is a large commitment for the company; however, as the storage of carbon must be continually monitored to insure it remains locked in storage and do not leak. A leak into the atmosphere of a large storage site would waste the energy used to compress and store it originally, meaning more $\mathrm{CO}_{2}$ would be released over all. There is also the potential should the leak under water for acidification of the surrounding water table. These risks increase with the size of the storage site and for that reason CCS is also not seen as a long term solution. The use of CCS comes with cost increase, $37.85 \%$ but could be used in the short term to reduce emissions whilst other pathways develop to the point where natural gas reforming is no longer an attractive option for hydrogen production.

Electrolysis stands out with the largest operating and capital costs of all four processes. The operating cost of electrolysis is larger due to the electricity required for production; this could be reduced by buying the excess grid power from renewable technologies. By using electricity from renewable sources, it would further benefit the environment by reducing fossil fuels burnt at power stations. The variability of the power from renewable sources does not affect the electrolysis process when a Polymer Electrolyte Membrane (PEM) reactor is used. When looking at the results presented in this research, even using high cost of grid price electricity, the electrolysis production cost is not elevated to the same degree as the other processes would be. This signifies the hydrogen yield from the process must be above the other processes.

Biomass gasification comes out at a highest production cost, at $9.168 \$ / \mathrm{kg}$, which is 5.24 times higher than the cost of steam reforming. This high cost is a combined result of a high capital cost when compared with steam reforming and a low yield when compared with electrolysis. More advanced techniques are still needed to be developed to decrease the production cost of hydrogen from biomass gasification. It is clear from Figure 4 that neither gasification nor electrolysis are economically attractive against steam reforming or steam reforming with CCS.

\subsection{Effects of feedstock}

The supply of feedstock is critical for the gasification process and maximising hydrogen yield. For any biomass feedstock, the ultimate analysis shows the average values of chemical composition including carbon, hydrogen, oxygen, nitrogen, sulphur, and minerals. Within this research, the composition of nitrogen, sulphur and minerals have been removed due to their insignificant size compared to those affecting hydrogen yields. Moisture contained in biomass was taken into consideration as the overall hydrogen percentage is influenced by the moisture content. It should be noted that all three feedstocks have moisture content below the required $35 \%$ vital for successful gasification ${ }^{[20]}$.

A comparison of feedstock type is presented in Figure 5. It can be seen that both poplar and sugar cane stand out as being of very similar average make up. The poplar feedstock contains $1 \%$ more hydrogen and has identical moisture content to sugar cane, however it can be seen that there is a vast difference in the purchasing price. The corn stover is the cheapest biomass analysed at $53.42 \$ / t$, whilst it contains the least hydrogen, it is also 
the driest on average at $22 \%$. The low moisture and purchase cost make corn stover a promising feedstock for gasification.

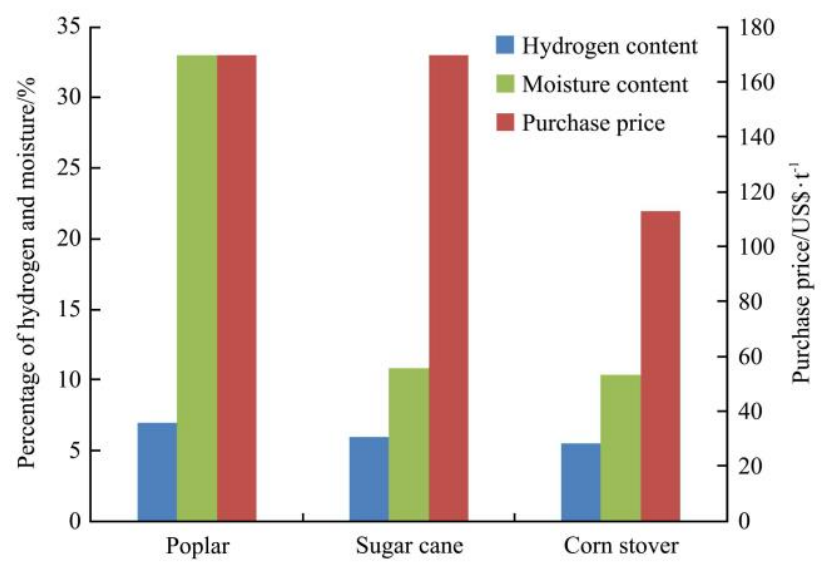

Figure 5 Comparison of biomass composition and purchase cost

The corn stover is considered as a suitable option for hydrogen production from gasification can also been reflected in Figure 6. Even though the hydrogen content of corn stover is lower than the other two feedstocks as shown in Table 1, however, the high mass yield and low cost again shows it is an attractive feedstock.

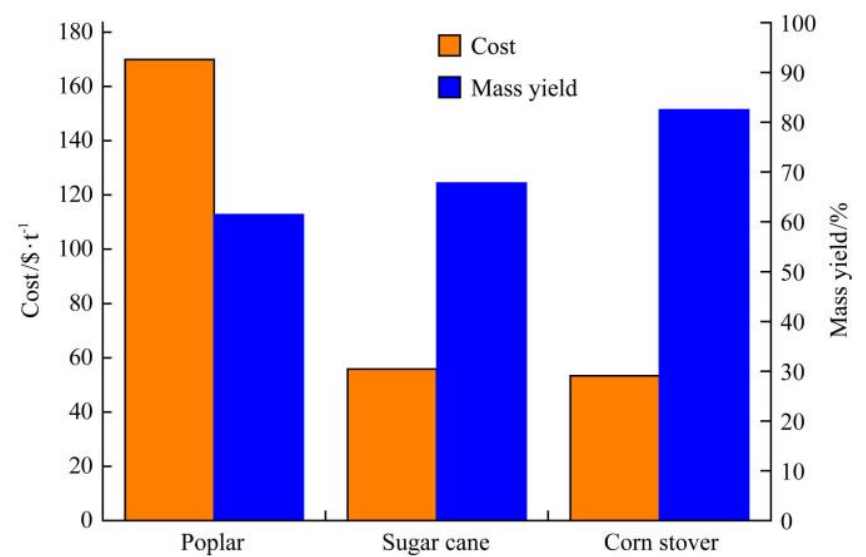

Figure 6 Comparison on mass yield and cost of gasification with three biomass feedstocks

Although other factors may affect the selection of feedstock for gasification, feedstock availability varies greatly by location and so the most profitable feedstock might not always be readily available near a production site. For example, Biomass in the UK might need to be imported from Sweden or Norway but this not only incurs cost of transportation, storage and treatment but also generates effects for the environment, such as driving up the $\mathrm{CO}_{2}$ output of the conversion process ${ }^{[25]}$. For the corn stover, one concern is that as a market developed, producers would be less focused on the production of food crops and so land could be repurposed and biodiversity lost. The high cost of poplar previously shown in Figure 6 can be explained in a similar way, with the cost increasing with demand.

\subsection{Opportunity for substitute fossil fuels using biomass}

The desire for countries to reduce their carbon output and fossil fuel consumption is increasing faster than the development of low carbon alternative technologies. Currently, power stations in most countries receive a subsidy to burn biomass alongside coal to reduce fossil fuel consumption. For emerging technologies that aim to make use of biomass feedstock, the attractiveness and economic benefit is directly reduced by the amount demand and cost of the feedstock increases. This is more prevalent when considered against the cost of fossil fuels and has the added effect of slowing the uptake and development of new technology. This is due to companies trying to maximise profit from their current established manufacturing process.

However, through careful management of feedstock sources and environmental impact studies, biomass gasification or electrolysis process (using renewable electricity generation) has the potential to cut carbon emissions. Following the government's coal/poplar subsidy, it can be seen that subsidy could be introduced for the industrial setup of new hydrogen producing technologies. This could be done on top of other carbon reduction incentives. This will be driven by hydrogen demand as more uses are found especially for transportation.

\section{Conclusions}

Different pathways for hydrogen production including traditional steam reforming, electrolysis, and novel biomass gasification, have been systematically compared within this research. The assessments methods involve energy analysis, exergy analysis and economic analysis. These assessments lead to a number of conclusions as follows: (1) Steam reforming remains the cheapest method of hydrogen production at $1.748 \$ / \mathrm{kg}$. This is due to its highly developed and refined state. However, steam reforming is not an ideal process currently or for 
the future, due to the large quantities of $\mathrm{CO}_{2}$. Due to its high yield, gasification and electrolysis remains competitive but requires relatively high initial and annual expenditure; (2) Both gasification and electrolysis are within range to be developed into alternative hydrogen production pathways. The energy and exergy efficiencies demonstrate the possibility for improvements to be made within the processes, whilst yields are already above that of steam reforming; (3) The use of the correct feedstock is key to maximise yield, a yield of $82.47 \%$ is possible with corn stover fed gasification; (4) Carbon capture and storage can be used to reduce $\mathrm{CO}_{2}$ output without the need to build a new plant and has no negative effect on hydrogen yield, only an increase in production cost; (5) The selection of feedstock should be determined by location, the increase in biomass production needs to be monitored with certain types removing biodiversity for the environment and having the potential to reduce food crop harvests.

\section{Acknowledgments}

The authors would like to sincerely thank the financial support from the National Natural Science Foundation of China (No. 51206044), the National Science Foundation of China (No. 71573084), the EPSRC pump-priming feasibility grant awarded by Institutional Sponsorship 2016-QUB (EP/P511225/1), and the Fundamental Research Funds for the Central Universities (No. 2016YQ07, No. 2015QN09).

\section{[References]}

[1] Hosseini S E, Wahid M A, Jamil M M, Azli A A M. A review on biomass-based hydrogen production for renewable energy supply. International Journal of Energy Research, 2015; 39(12): 1597-1615.

[2] Roger G G. How much hydrogen is produced in the United States. Eco Global Fuels, 2015. Available: http://ecoglobalfuels.com/news/how-much-hydrogen-produce d-united-states. Accessed on [2015-09-10].

[3] Aghamohammadi N, Reginald S S, Shamiri A, Zinatizadeh A A, Li P W, Sulaiman N M B N. An investigation of sustainable power generation from oil palm biomass: a case study in Sarawak. Sustainability-Basel, 2016; 8(5): 416-418.
[4] Hawa B, Elif K. Hydrogen from biomass- Present scenario and future prospects. International Journal of Hydrogen Energy, 2010; 35(14): 7416-7426.

[5] Trevor L L, Anthony R R, Maohong F. The progress in water gas shift and steam reforming hydrogen production technologies-a review. International Journal of Hydrogen Energy, 2014; 39(30): 16983-17000.

[6] Trevor L L, Anthony R R, Maohong F. Development of catalysts for hydrogen production through the integration of steam reforming of methane and high temperature water gas shift. Energy, 2015; 90(1): 748-758.

[7] Li Y M, Fu P, Yi W M, Bai X Y. Hydrogen production by steam reforming of acetic acid and bio-oil using $\mathrm{Ni} / \gamma-\mathrm{Al} 2 \mathrm{O} 3$ catalysts. Int J Agric \& Biol Eng, 2015; 8(6): 69-76.

[8] Demirbas A, Arin G. An overview of biomass pyrolysis. Energy Sources, 2002; 24(5): 471-485.

[9] Evans R J, Chornet E, Czernik S, Feik C, French R, Phillips $\mathrm{S}$, et al. Renewable hydrogen production by catalytic steam reforming of peanut shells pyrolysis products. Acs Fuel Chem, 2002; 47(2): 757-758.

[10] Padró C E G. The road to the hydrogen future: Research \& development in the hydrogen program. Acs Fuel Chem, 1998; 43(3): 353-357.

[11] Jalana R K, Srivastavaa V K. Studies on pyrolysis of a single biomass cylindrical pellet-kinetic and heat transfer effects. Energy Conversion and Management, 1999; 40(5): 467-494.

[12] Prakash P, Sheeba N. Hydrogen production from steam gasification of biomass: Influence of process parameters on hydrogen yield-A review. Renewable Energy, 2014; 66: 570-579.

[13] Dermirbas A. Hydrogen production from biomass by the gasification process. Energy Sources, 2002; 24(1): 59-68.

[14] Butterman H C, Castaldi M J. $\quad \mathrm{CO}_{2}$ as a carbon neutral fuel source via enhanced biomass gasification. Environmental Science \& Technology, 2009; 43(23): 9030-9032.

[15] Lau F S, Bowen D A, Dihu R, Doong S, Hughes E E, Remick $\mathrm{R}$, et al. Techno-economic analysis of hydrogen production by gasification of biomass. Gas Technology Institute, 2002. Available: https://www.osti. gov/scitech/biblio/816024. Accessed on [2016-09-12].

[16] Kenia G D S, Caroline T E, Eduardo D R, Reinaldo A B, Elisandro P F, Cleber A L, et al. Hydrogen production in the electrolysis of water in Brazil, a review. Renewable and Sustainable Energy Reviews, 2017; 68(1): 563-571.

[17] Nicoletta P, Fabrizio B, Alessandro T. A two-tier approach to the optimization of a biomass supply chain for pyrolysis processes. Biomass and Bioenergy, 2016; 84: 87-97.

[18] Tanger P, Field J L, Jahn C E, DeFoort M W, Leach J E. 
Biomass for thermochemical conversion: targets and challenges. Frontiers in Plant Science, 2013; 4(11): 218-218.

[19] Gielen D, Moriguchi Y. CO in the iron and steel industry: an analysis of Japanese emission reduction potentials. Energy Policy, 2002; 30(10): 849-863.

[20] Wu Y S, Yang W H, Blasiak W. Energy and exergy analysis of high temperature agent gasification of biomass. Energies, 2014; 7(4): 2107-2122.

[21] French R, Bair K M, Czernik S, Parent Y, Ritland M, Chornet E. Fluidizable catalysts for hydrogen production hydrogen from steam reforming biomass pyrolysis products. Acs Fuel Chem, 2002; 47(2): 759-760.

[22] Acomb J C, Wu C, Williams P T. The use of different metal catalysts for the simultaneous production of carbon nanotubes and hydrogen from pyrolysis of plastic feedstocks.
Applied Catalysis b-Environmental, 2016; 180: 497-510.

[23] Wilckens R S, Linnemann J, Trumper S. Cost models for current and future hydrogen production. Research gate, 2007. Available: https://www.ika.rwth-aachen.de/r2h/images/ d/d6/ Roads2HyCom_R2H2020PU_-_H2_Production_Cost_ Models.pdf. Accessed on [2015-11-12].

[24] Milne $\mathrm{T}$ A, Evans R J, Abatzaglou N. Biomass gasifier"tars": Their nature, formation, and conversion. Nrel, 1998. Available: http://www.ps-survival.com/PS/ Gasifiers/Biomass_Gasifier_Tars_Their_Nature_Formation_ And_Conversion_1998.pdf. Accessed on [2015-06-12].

[25] James H. Flows of biomass to and from the EU-an analysis of data and trends. Fern, 2011. Available: http://www.fern.org/sites/fern.org/files/Biomass\%20imports $\% 20$ to $\% 20$ the $\% 20$ EU\%20 final_0.pdf. Accessed on [2016-08-21]. 